\title{
Prevalence of Bilirubin Encephalopathy in Calabar, South-South, Nigeria (A 5-Year Review)
}

\author{
Sunday O. Ochigbo*, Ifeoma Venn and Anachuna Kingsley
}

Department of Paediatrics, University of Calabar, Calabar, Nigeria

\begin{abstract}
Background: Bilirubin encephalopathy is the clinical syndrome associated with bilirubin toxicity to the central nervous system resulting in chronic and permanent sequelae. It has been estimated that approximately $60 \%$ of term babies and $80 \%$ of preterm babies develop jaundice within the first week of life.

Objective: To determine the prevalence, morbidity and mortality of bilirubin encephalopathy at our centre.

Methodology: A retrospective descriptive review of the case files of all babies diagnosed with bilirubin encephalopathy over the past 5 years from January 2010 to December 2014 was undertaken. Information retrieved from the case notes included age, sex, presence of fever, duration of illness, place of delivery, causes and treatment. The outcome measures such as discharged home, discharged against medical advice, and death were also noted.

Results: Out of a total of 2,820 babies, $21(0.74 \%)$ were admitted on account of bilirubin encephalopathy. Of these 21 , seventeen (81\%) were males and four (19\%) females giving M; F ratio of 5:1. Eighteen babies (85.7\%) had pyrexia, $8(38.1 \%)$ and $6(28.6 \%)$ were hypertonic and hypotonic respectively on admission. Only $33.3 \%$ of the deliveries took place in the health facilities. The established factors responsible for jaundice included infections (septicaemia) (15/71.4\%), ABO incompatibility (4/19.1\%), and G6PDeficiency (2/9.5\%). The mean maximum serum bilirubin of the subjects was $321.3 \mu \mathrm{mol} / \mathrm{l}(242.5-440.3)$. The case fatality was $4 / 21(19 \%)$.

Conclusion: Neonatal septicaemia is associated with bilirubin encephalopathy. Therefore identification and prompt treatment is of utmost importance to avoid morbidity and mortality.
\end{abstract}

Keywords: Bilirubin, Kernicterus, Exchange Blood Transfusion, infections.

\section{INTRODUCTION}

Bilirubin is the breakdown product of haem, a content/component of the red blood cells. A rise in blood levels of this pigment can cause jaundice, a yellow colouration of the skin and sclera. Neuronal damage/toxicity occurs as a result of increased concentration of unconjugated/free or unbound bilirubin in the blood. Unconjugated bilirubin crosses the blood brain barrier when the bilirubin binding capacity is exceeded. Bilirubin encephalopathy (BE) is the clinical syndrome associated with bilirubin toxicity to the central nervous system while Kenicterus is the pathological or anatomic diagnosis made at autopsy resulting in chronic and permanent sequel. Schmorl first used the term kernicterus as early as 1903 [1]. The causes of hazardous hyperbilirubinemia vary in different populations, with Rhesus isoimmunisation more common in Europe [2, 3] glucose-6-phosphate dehydrogenase (G6PD) deficiency predominating in the United States and Canada [4, 5]. Conditions like infections, prematurity, acidosis, asphyxia, hypoalbumineamia may facilitate bilirubin penetration of brain tissue [4]. It has been estimated that approximately $60 \%$ of term babies and $80 \%$ of preterm

*Address correspondence to this author at the Department of Paediatrics, University of Calabar, Calabar, Nigeria; Tel: +23 47063930682;

E-mail: ochigbosunny@gmail.com babies develop jaundice in the first week of life, and about $10 \%$ of breastfed babies are jaundiced at one month of age [4]. Severe Neonatal jaundice is 100 fold more frequent in Nigeria than industrialized countries [2]. A recent study in Ife and llesha, Nigeria reported that $30 \%$ of babies with severe jaundice who had Exchange Blood Transfusion (EBT) already had features of Bilirubin encephalopathy [6]. Most estimates of the incidence of chronic bilirubin encephalopathy (CBE) have been in the range of $1 / 100000[2,7]$ but a recent study from Canada revealed a higher incidence of 2.3/100 000 .

In view of the aforementioned we conducted a review of bilirubin encephalopathy in Calabar over the past $5 y e a r s$ to ascertain the burden of the condition.

\section{SUBJECTS AND METHODS}

This retrospective descriptive study was conducted in the Neonatal units of the department of Paediatrics, University of Calabar Teaching Hospital (UCTH) situated in Southern Nigeria. The units previously described by Udo et al. [8] care for the inborn and out born babies referred to the hospital. A review of the case files of these babies diagnosed with bilirubin encephalopathy over the past 5 years from January 2010 to December 2014 was undertaken. A standard protocol for the diagnosis of Bilirubin encephalopathy and Exchange Blood Transfusion (EBT) as treatment 
options in the newborn unit had been established at our centre. This included the serum bilirubin $\geq 20 \mathrm{mg} / \mathrm{dl}$, rate of rise $\geq 5 \mathrm{mg} / \mathrm{dl} /$ day, bilirubin $\geq 10 \%$ body weight especially for preterm's and clinical features suggestive of Bilirubin Induced Neurological Deficit (BIND). In addition phototherapy was administered on all babies with jaundice whose serum bilirubin was $>10 \mathrm{mg} / \mathrm{dl}$ as well as prophylactic phototherapy for plethoric babies. Information retrieved from the case notes included age, sex, presence of pyrexia, duration of illness, place of delivery, causes and treatment among others. The total number of admissions seen during the period was obtained from the ward registers. All infants were managed by Consultants and members of the team.
Outcome measures including discharged home, discharged against medical advice, neurologic sequelae and deaths were extracted. Data was analysed using Statistical Package for Social Sciences (SPSS) version 20. Descriptive statistics was carried out using means and standard deviations and P-value was regarded as statistically significant if less than 0.05 .

\section{RESULTS}

A total of 2,820 babies were admitted during the review period. Of this, 553(19.6\%) had Neonatal jaundice, $21(3.8 \%)$ out of the jaundiced babies had bilirubin encephalopathy (BE). Considering all babies

Table 1: Socio-Demographic Characteristics of Mothers of Babies with Bilirubin Encephalopathy

\begin{tabular}{|c|c|c|c|}
\hline Variable & Frequency & Percentages (\%) & P-Value \\
\hline \multicolumn{4}{|l|}{ Age groups (yrs) } \\
\hline $18-25$ & 5 & 23.9 & \multirow{5}{*}{$0.048^{*}$} \\
\hline $26-30$ & 7 & 33.3 & \\
\hline $31-35$ & 7 & 33.3 & \\
\hline $36-40$ & 2 & 9.5 & \\
\hline$>40$ & 0 & 0 & \\
\hline Total & 21 & 100 & \\
\hline \multicolumn{4}{|l|}{ Occupation } \\
\hline Housewife & 5 & 23.9 & \multirow{5}{*}{0.090} \\
\hline Civil Servant & 4 & 19.0 & \\
\hline Business & 2 & 9.5 & \\
\hline Petty traders & 10 & 47.6 & \\
\hline Others & 0 & 0 & \\
\hline Total & 21 & 100 & \\
\hline \multicolumn{4}{|l|}{ Educational Status } \\
\hline None & 4 & 19.0 & \multirow{4}{*}{$0.011^{*}$} \\
\hline Primary & 8 & 38.1 & \\
\hline Secondary & 6 & 28.6 & \\
\hline Tertiary & 3 & 14.3 & \\
\hline Total & 21 & 100 & \\
\hline \multicolumn{4}{|l|}{ Parity } \\
\hline 1 & 3 & 28.5 & \multirow{5}{*}{$0.025^{\star}$} \\
\hline 2 & 5 & 23.9 & \\
\hline 3 & 7 & 33.3 & \\
\hline 4 & 3 & 14.3 & \\
\hline$>5$ & 0 & 0 & \\
\hline Total & 21 & 100 & \\
\hline
\end{tabular}

*Statistically significant. 


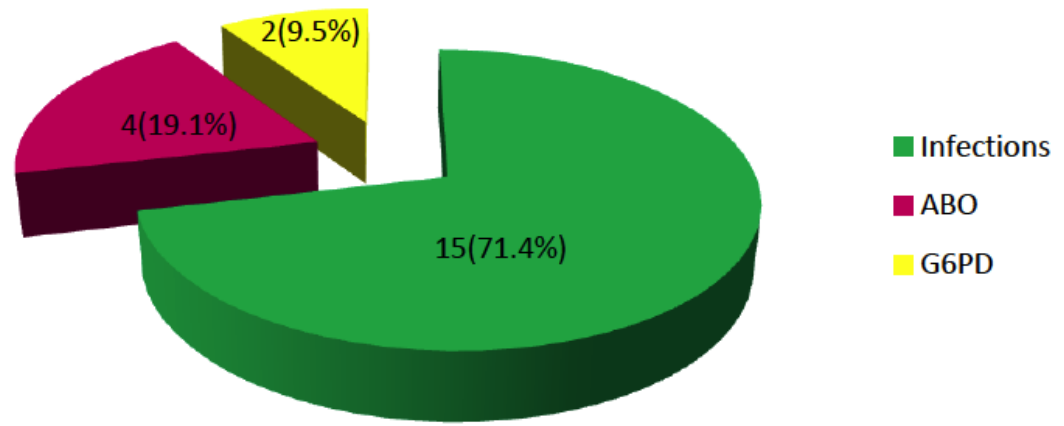

Figure 1: Risk factors for Bilirubin Encephalopathy.

admitted into the units, the prevalence of BE was $0.74 \%$. Of the 21 babies with $B E$, seventeen $(81 \%)$ were males and four $(19 \%)$ females giving $\mathrm{M}$ : $\mathrm{F}$ ratio of $5: 1$. The mean age and weight of the babies were 13 days (2-28 days) and $2.88 \mathrm{~kg}(1.2-4.2 \mathrm{~kg})$ respectively. The mean duration of illness and treatment was 3days (8hrs-14days). All the babies that presented with bilirubin encephalopathy within this period were all out born. Eighteen babies $(85.7 \%)$ had pyrexia prior to admission, $8(38.1 \%)$ and $6(28.6 \%)$ were hypertonic and hypotonic respectively. The mean duration of jaundice prior to admission was 3.2 days. Seventeen $(81 \%)$ of the mothers had antenatal care (ANC). The mean age of the mothers was \pm 28 years $(18-40$ years). The highest prevalence was observed between the ages 26-35 years $(P=0.048)$. Majority of the mothers were petty traders $47.6 \%(P=0.090)$ and most had only primary education $38.1 \% \quad(P=0.011)$ and multiparous mothers $33.3 \%(P=0.025)$ (Table 1$)$.

The places of delivery of the babies were hospital (33.3\%), home (28.6\%), Traditional Birth Attendants (TBA) $28.6 \%$, and churches (9.5\%). Nineteen $(90.5 \%)$ babies were delivered via Spontaneous Vaginal Delivery (SVD), while 2(9.5\%) had Caesarean Section (CS). Ten $(47 \%)\left(X^{2}=1.285\right)$, babies were delivered at term while preterm delivery accounted for $8(38 \%)$ $\left(X^{2}=0.142\right) \quad($ Table 1). The established factors associated with $\mathrm{BE}$ included infections (septicaemia) 15 (71.4\%), ABO incompatibility 4 (19.1\%), and G6P Deficiency 2 (9.5\%) (Figure 1). Of the 15 babies who had infections, only 5(33.3\%) were delivered in the health facilities. The mean duration of admission was 8.6 days. None of the babies that died had documented evidence of the use of herbal drugs, Camphor (Naphthalene balls), mentholatum or other medicinal agents.

Term, pre-term and post-term babies constituted $47.7 \%, 38 \%$ and $14.3 \%$ respectively (Table 2 ). The mean serum bilirubin of the subjects was $321.3 \mu \mathrm{mol} / \mathrm{l}$
(242.5 - 440.3). Exchange Blood Transfusion (EBT) was performed on $17(81 \%)$ babies. Parents who took their babies home against medical advice were four $(19 \%)$, seven $(62 \%)$ were discharged home. A total of $431 / 2820(15.3 \%)$ babies died during the period. Eight (8) out of the 21 babies who had bilirubin encephalopathy died with case fatality of $38 \%$. Of the seven babies discharged to the neurology clinic, only two maintained regular clinic visits with cerebral palsy and microcephaly as sequalae, the rest were lost to follow up.

Table 2: Maturity Indices of Babies who Died due to Bilirubin Encephalopathy

\begin{tabular}{|c|c|c|}
\hline Delivery & No. of Deaths (21) & $\mathbf{X}^{2}$ \\
\hline \hline Pre-Term & $8(38 \%)$ & 0.142 \\
\hline Term & $10(47.7 \%)$ & 1.285 \\
\hline Post term & $3(14.3 \%)$ & 2.285 \\
\hline
\end{tabular}

$\mathrm{X}^{2}=3.71 ; \mathrm{P}$ Value $=0.156 ; \mathrm{DF}=2$

\section{DISCUSSION}

The prevalence of bilirubin encephalopathy in this study was observed to be $0.74 \%$ of all newborn admissions. Ogunlesi et al. reported prevalence rates of $3.4 \%$ and $2.3 \%$ from two tertiary health centres in Sagamu and Ilesha in South- west Nigeria respectively [9]. Our prevalence is however higher than the study among Canadian children which was 2.3 per 100,000 births [3], Danish study also observed incidence of 0.6 per 100,000 [5] as well as the study by Brooks et al. recorded incidence of 0.44 per 100,000 births among Californian children [4]. The comparatively high prevalence in this study could be due to the low socioeconomic status, literacy level, increased birth order which were observed to be statistically significant association with $\mathrm{BE}$.

Most of the babies were delivered at term, this is at variance with other studies that had more preterm 
babies presenting with kernicterus [10, 11]. A Danish study did not identify any risk factor throughout pregnancy or delivery associated with subsequent development of kernicterus [12]. Majority of the deliveries in this study were spontaneous vaginal deliveries conducted in unorthodox places, hence vertical transmission of infection might be the likely cause of septicaemia. In a systemic review and metaanalysis by Grace et al. [13] they observed that pregnant mothers with laboratory confirmed infections $17 \%$ of their newborns had positive laboratory cultures for infection and mothers with clinical signs of infection, $20 \%$ of newborns had positive laboratory cultures for infections.

This was corroborated by studies from Abakaliki [14], Ife [15], Benin [16], but at variance with other reviews from Canada [3], UK and Ireland [8, 17]. In addition the poor personal hygiene which is usually observed among mothers and care givers from the low socioeconomic status who form the bulk of our patients may further predispose the babies to infections. These findings are in keeping with the study by Ogunlesi et al. [18] who also found that most of the mothers with tertiary education and good knowledge had better health care seeking behaviour for newborn jaundice and their infants did not manifest with bilirubin encephalopathy.

In line with the policy and protocol of our centre, Exchange Blood transfusion (EBT) was done for the babies with bilirubin encephalopathy to avoid further damage even though they reported to the facility with signs of bilirubin Induced Neurologic deficit [1]. It was noticed from the US Kernicterus registry that neurological sequalae can be reversed with early EBT $[11,19,20]$.

The low clinics turn out after discharge may be due to parents seeking for alternative therapy in unorthodox places as observed from this study or babies may have died. The case fatality observed could have resulted from cardio respiratory failure due to profound encephalopathy.

\section{CONCLUSION AND RECOMMENDATIONS}

Bilirubin encephalopathy still remains a cause of death among neonates in Nigeria. This study emphasizes the need to focus more attention on early identification and treatment of septicaemia as a risk factor for bilirubin encephalopathy. Early and timely intervention with exchange blood transfusion is paramount. Education of mothers on specific kernicterus prevention strategy is recommended

\section{COMPETING INTEREST}

None.

\section{FUNDING}

None.

\section{REFERENCES}

[1] NICE. Neonatal Jaundice. CG98. London: National Institute for Health and Clinical Excellence 2010.

[2] Slusher TM, Olusaniya BO. Neonatal jaundice in low- and middle-income countries. Care of the jaundiced neonate. New York: McGraw-Hill 2012: 263-73.

[3] Sgro M, Campbell DM, Kandasamy S, Shah V. Incidence of chronic bilirubin encephalopathy in Canada. Pediatrics 2012; 130: e886-90.

[4] Brooks JC, Fisher-Owens SA, Wu YW, Strauss DJ, Newman TB. Evidence suggests there was not a "resurgence" of kernicterus in the 1990s. Pediatrics 2011; 127: 672-9. http://dx.doi.org/10.1542/peds.2010-2476

[5] Ebbesen F, Andersson C, Verder H, et al. Extreme hyperbilirubinaemia in term and near-term infants in Denmark. Acta Paediatr 2005; 94: 59-64. http://dx.doi.org/10.1080/08035250410022170

[6] Owa JA, Ogunlesi TA. Why we are still doing so many exchange blood transfusion for neonatal jaundice in Nigeria. World J of Pediatr 2009; 5: 51-5. http://dx.doi.org/10.1007/s12519-009-0009-2

[7] Manning D, Todd P, Maxwell M, Jane Platt M. Prospective surveillance study of severe hyperbilirubinaemia in the newborn in the UK and Ireland. Arch Dis Child Fetal Neonatal Ed 2007; 92: F342-6.

[8] Udo JJ, Anah MU, Ochigbo S O. Neonatal morbidity and mortality in Calabar. A hospital based study. Nig J Clin Pract 2008; 11: 285-9.

[9] Ogunlesi TA, Dedeke IO, Fetuga MB, Ogunfowora OB. The incidence and outcome of bilirubin encephalopathy in Nigeria; a bicentre study. Nig J Med 2007; 16: 354-9.

[10] Christensen RD, Lambert DK, Henry E, et al. Unexplained extreme hyperbilirubinemia among neonates in a multihospital healthcare system. Blood Cells Mol Dis 2013; 50: 105-9.

http://dx.doi.org/10.1016/j.bcmd.2012.10.004

[11] Johnson L, Bhutani VK, Karp K, Sivieri EM, Shapiro SM. Clinical report from the pilot USA. Kernicterus Registry (1992 -2004). J Perinat 2009; 29(Suppl 1): S25-45.

[12] Gamaleldin R, Iskander I, Seoud I, et al. Risk factors for neurotoxicity in newborns with severe neonatal hyperbilirubinemia. Pediatrics 2011; 128: e925-31. http://dx.doi.org/10.1542/peds.2011-0760

[13] Grace JC, Ann CL, Abdullah HB, Jingwen T, Robert EB. Prevalence of early-onset neonatal infection among newborns of mothers with bacterial infection or colonization: a systematic review and meta-analysis. BMC Infect Dis 2015; 15: 118. http://dx.doi.org/10.1186/s12879-015-0813-3

[14] Onyearugha CN, Onyire BN, Ugboma HA. Prevalence and associated factors as seen in Federal Medical Centre Abakaliki, South East Nigeria. J Clin Med Res 2011; 3: 40-5. 
[15] Owa JA, Taiwo O, Adebiyi JA, Dogunduro SA. Neonatal jaundice at Wesley Guild hospital llesa and Ife state hospital Ile Ife. Nig J Pediatr 1989; 16: 23-30.

[16] Israel-Aina $\mathrm{YI}$, Omoigberale Al. Risk factors for neonatal jaundice in babies presenting at UBTH, Benin City. Nig $\mathrm{J}$ Pediatr 2012: 39: 159-63.

http://dx.doi.org/10.4314/njp.v39i4.2

[17] Micheal WK, Andrea CW, Yvonne W, et al. Incidence, etiology and outcomes of hazardous hyperbilirubinaemia in Newborns. Pediatrics 2014; 134: 504-9.

http://dx.doi.org/10.1542/peds.2014-0987
[18] Ogunlesi TA, Abdul AR. Maternal knowledge and care seeking behavior for Newborn jaundice in Sagamu, South west Nigeria. Nig J Clin Pract 2015; 18: 33-40.

[19] Maimburg RI, Madsen B. Danish children with validated diagnosis of Kernicterus. Acta Obst Gyne Soc 2009; 88: 1011-6.

http://dx.doi.org/10.1080/00016340903124917

[20] Hansen TW, Nietsch L, Norman E, et al. Reversibility of acute intermediate phase bilirubin encephalopathy. Acta Paediatr 2009; 98: 1689-94.

http://dx.doi.org/10.1111/j.1651-2227.2009.01409.x 